\title{
8 Therapeutic Presence in Mediated Psychotherapy: the Uncanny Stranger in the Room
}

\author{
Sheryl Brahnam
}

\begin{abstract}
Taking the perspective of the therapist, this chapter reflects on how both the lack of important physical cues and the addition of media artifacts, such as audio/ video synchronization problems and technological glitches, in distance psychotherapy using the telephone and videoconferencing technologies can potentially affect the therapeutic relationship and therapeutic presence.
\end{abstract}

Keywords: Presence; Therapeutic Presence; Therapeutic Relationship; Distance Psychotherapy; Distance Psychoanalysis; Skype.

\subsection{Introduction to Chapter 8}

Mediated psychotherapy is as old as the profession of psychotherapy itself, which is said to have been invented as a medical profession in the 1890s when Sigmund Freud undertook a self-analysis thereby becoming the first analyst (Cushman, 1992). Freud's letters to his friend Wilhelm Fliess were an important instrument in his selfanalysis, and it was Freud who first demonstrated the value of using correspondence therapeutically in his letters of advice to the father of "Little Hans," a five-year-old boy with a phobia of horses (Freud, 1959). By the end of the 1950s, many analysts were describing their ventures in analysis through letters (Grotijahn, 1955), but letter writing was not the sole form of mediation psychoanalysts were exploring that decade. In 1959 a closed-circuit link was set up between the University of Nebraska and Norfolk State Hospital to provide psychiatric and other health services (Rees \& Haythornthwaite, 2004), and in 1953 the Samaritans started using the telephone as a crises intervention tool for suicide (Grumet, 1979), an intervention so successful that by the 1970s a plethora of community hotlines and crises call centers had been established (Hornblow \& Sloane, 1980). The 1970s also witnessed a wave of experimentation with the telephone's potential for other therapeutic functions, ranging from distance psychotherapy (Grumet, 1979) to telephone hypnosis (Owens, 1970) to "videotelephone" consultations (Maxmen, 1976). In the 1990s the first forays into distance psychotherapy using the Internet were launched, beginning around 1995 with online advice services and rapidly developing by the end of the decade into offering a full range of psychological services via real-time chat, videoconferencing, and encrypted email (Ainsworth, 2002). Today videoconferencing technologies routinely link specialists at academic and regional mental health centers to remote centers around the world, and internet psychotherapy is slowly but increasingly being accepted, at least as an adjunctive modality, by psychotherapists and clients alike. 
Despite the early adoption in psychiatry of videoconferencing technologies and the many studies indicating its reliability, effectiveness, and patient satisfaction (Hilty, Marks, Urness, Yellowlees, \& Nesbitt, 2004) and despite the accessibility of similar technologies available on the Internet, such as Skype, and the many studies attesting to the Internet's therapeutic value (Barak, Hen, Boniel-Nissim, \& Shapira, 2008), many psychotherapists continue to express skepticism and reservations about employing videoconferencing, the telephone, Skype, and other internet tools, such as chat and email, as the primary means of communicating and interacting with clients (Lester, 2006), citing concerns not only with opening a Pandora's box of legal and ethical issues (Koocher, 2007) but also, and more importantly, with having a negative impact on what is considered by many theoretic viewpoints to be the most vital instrument of change: the therapeutic relationship. Operationally defined as the feelings and attitudes the therapist and client have for one another and how these are expressed, the therapeutic relationship is held to account for the highest outcome variance (33\% or more) across all theoretical orientations (Lambert, 1992).

The literature is mixed, however, regarding the impact mediation has on the therapeutic relationship, with some studies reporting positive or at least similar influences compared with face-to-face encounters (Reynolds, Stiles, \& Grohol, 2006), while other studies report adverse mediation effects on the relationship (Rees \& Stone, 2005). A limitation of many of these studies is that they have focused almost exclusively on one component of the therapeutic relationship: the alliance, defined as the affective bond between client and therapist and the extent to which they work together collaboratively and purposely (Bordin, 1979). There are at least two reasons for this focus. First, it is commonly asserted that alliance predicts outcome (Martin, Garske, \& Davis, 2000); however, there is a small but growing body of literature that questions the validity of this assertion (Barber, Khalsa, \& Sharpless, 2010). Second, there is a tendency to define the therapeutic relationship solely in terms of the alliance, which is a gross oversimplification (Stiles \& Goldsmith, 2010). According to Gelso and Hayes (1998), for instance, all therapeutic relationships have at least three components: a working alliance, a transference/countertransference configuration (that is, the repetition and reliving of earlier relational patterns with significant others within the therapeutic relationship), and the real relationship. Norcoss (2010) presents an even more elaborate view of the therapeutic relationship, with the alliance being but one ingredient among many. Another limitation in these studies concerns the way in which the alliance is measured, which can be from the perspective of the client, the perspective of the therapist, or the perspective of the expert observer. Most studies measuring the impact mediation has on the alliance have taken the perspective of the client because research has shown the strongest correlation between the client's views of the working alliance and outcomes (Bachelor \& Horavath, 1999), especially in the early stages of the relationship (Kokotovic \& Tracey, 1990), while therapist reservations and expressions of concern using these technologies and their impact on the alliance, if addressed at all, are typically dismissed as normal resistances to change or as a lack 
of experience with the new technologies (Rees \& Stone, 2005). Client-centric views of the alliance measured in the early stages, however, may present a premature picture of the alliance (Castonguay, Constantino, \& Grosse, 2006). Many have argued that the alliance changes over time (Stiles \& Goldsmith, 2010); it ruptures and is rebuilt (Eubanks-Carter, Muran, \& Safran, 2010), providing corrective emotional experiences for the client and powerful opportunities for change (F. Alexander \& French, 1946).

According to J.F. Alexander, Holtzworth-Munroe, and Jameson (1994), many psychotherapists find empirical research unappealing and remain largely uninfluenced by it because it fails to capture what they perceive to be essential aspects of the phenomenon. My intention in this chapter is to address the concerns of therapists, not by writing them off as mere discomfort working with unfamiliar technologies, but rather by acknowledging them for what they are reported to be: modalities affecting the clinician's ability to influence the relationship-to attend to the subtleties of client expressions and to the clinician's own reactions and experiences. Some of these concerns involve the sensorial imposition of what I have labeled elsewhere media artifacts (Brahnam, 2009, 2012), with the sense of the word artifact taken from Webster's Third New International Dictionary as "a product of artificial character due to extraneous agency" (Gove, 1986, p. 124). Media artifacts, such as synchronization problems between audio and video and technological glitches, can unconsciously alter and transform participants' impressions of each other, perturbing, for the clinician, the psychological and physical presence of the client-potentially introducing into the therapeutic frame the presence of something akin to an uncanny stranger in the room.

Although few in number and mostly in the field of telepsychiatry, there are papers and studies that have associated various media artifacts with a concept of presence. An early work is that of Cukor et al. (1998), who examined video artifacts in relation to social presence (see also Chapters 1, 5 and 6, this volume), a term first introduced by Short, Williams, and Christie (1976) and defined as "a quality of the communications medium" that expresses "the degree of the salience of the other person in the interaction and the consequent salience of the interpersonal relationships" (p. 65). Cukor et al. found video in telepsychiatry establishing a baseline sense of social presence; but video artifacts, some of which were acknowledged to be subtle, were speculated to reduce the effectiveness of the video channel for conveying information to psychiatrists about their patients. More recently, Turner (2006) related media artifacts to the idea of presence as it is conceptualized in the field of virtual reality, often as the "sensation of being there" in the virtual world (Barfeld, Zeltzer, Sheridan, \& Slater, 1995) or as the "perceptual illusion of non-mediation” (Lombard \& Ditton, 1997). ${ }^{1}$ His goal was to show that the illusion of non-mediation creates the impression

1 It should also be noted that there are a number of papers that address presence in virtual reality psychotherapy, especially in relaxation therapy (Villani, Riva, \& Riva, 2007) and in virtual exposure therapy (VET) (Lu, Harter, \& Pierce, 2011; Meyerbröker \& Emmelkamp, 2011; Riva, 2005), with the 
that all the bodily cues relevant to a therapeutic interaction are available, when in fact they are not (for a broader discussion on the concept of presence see Chapters 1 , 2 and 3 , this volume).

My goal is to reflect both on what is missing in mediation (corporality) and what is being added (the presence of media artifacts/agencies) and to explore how the qualities of the media (specifically, the telephone and Skype) affect the therapeutic relationship by disturbing what is known as therapeutic presence, that is, the therapist's intricate and multifaceted awareness of the client. To accomplish this goal, I begin by briefly reviewing the concept of therapeutic presence, mostly as it is defined and described in humanistic and psychodynamic writings. ${ }^{2}$ This overview of therapeutic presence is then followed by a discussion of media artifacts, or mediation agencies as they might best be described here, and how they perturb the ability of psychotherapists to "use their selves and their attuned bodily awareness as tools" for understanding their clients as well as for perceiving "how their responses are facilitating the client's therapeutic process and the therapeutic relationship" (Geller \& Greenberg, 2012, p. 7).

\subsection{Therapeutic Presence}

As indicated above, researchers have not identified all client/therapist factors that contribute to the development of a beneficial therapeutic relationship, but according to Geller, Greenberg, and Watson (2010) therapeutic presence, which they define as being in the moment with the client on multiple levels (physical, emotional, cognitive, and spiritual), is a necessary condition for a positive therapeutic relationship; and they present empirical evidence to support this claim. ${ }^{3}$ In an early exploratory paper on therapeutic presence, Geller and Greenberg (2002) found in their examination of solicited accounts from expert therapists practicing a range of theoretical

concern of the latter being primarily on providing patients with enough presence to feel anxiety when presented with a fear provoking stimulus. For more on presence in virtual reality stress management and in VET, see chapter 10.

2 My arguments in this chapter, however, equally apply to other therapeutic modalities, including cognitive behavioral therapy (CBT). Although not generally seen as highly central, the therapeutic relationship in all its complexity is still relevant in CBT (Gelso \& Hayes, 1998). There are even CBT orientations that stress therapeutic presence (see, for example, Friedberg, Tabbaraha, \& Poggesia, 2013).

3 As with many alliance studies, client perceptions of presence, and not therapist perceptions, are associated with positive outcome. Geller et al. (2010) note two possible reasons for this incongruity: 1) therapists may not always be able to communicate presence, even though they may be experiencing it, and 2) some clients may have difficulty experiencing presence as well as relational connectivity. The authors point out that studies are needed to isolate the qualities and attachment styles that allow a client to experience presence. 
orientations-but all acknowledging the importance of presence-that presence prepares the ground for an attuned responsiveness to the client that is made possible by combining a kinesthetic and emotional sensing of the client's affect (receptivity) with an inward attendance to the way in which the experience of the client resonates in the therapist's own body (inward attendance). The receptivity that therapists report is a bodily receptivity achieved by listening "deeply to their clients with all of their senses and perceptions," perceiving what clients are saying beyond words and their expression. As one therapist put it, "it's just not listening to the words, listening to the tone, listening to what the person's bodily experience is...but somehow listening with my body to their bodily experience" (p. 78). Inward attendance is described as transforming the self of the therapist into a finely tuned instrument, where everything that is experienced inside (images, feelings, bodily sensations, and memories) is used to inform the therapeutic process. Through receptivity and inward attendance, the body of the therapist becomes a sensitive sensor attuned to the self, to the client, and to the relationship. The goal of therapeutic presence is to enable the client to feel fully perceived and understood. Thus, therapeutic presence (the inner resonance and feeling of connection to the client that the therapist experiences) needs to be communicated to the client. When clients feel understood, they elaborate and delve more deeply into what they are feeling in the moment and eventually learn to understand and validate their own experiences. ${ }^{4}$

The focus in therapeutic presence on the body is not surprising. From the start the development of interpersonal connections and the body are closely tied. Within the shared embodied space between infant and mother, the infant learns to locate its own body by exhibiting a "lived sense of corporeal equivalencies (your tongue, my tongue)" (Crossley, 1996, p. 51) and by actively assuming the gestures of those around it, eventually investing them with intentionality so that "here the others' intentions," as Merleau-Ponty (1964) observes of the infant, "somehow play across my body while my intentions play across his” (p. 119). According to Schore (2000), in the infant's first year, visual experiences play a predominant role in social and emotional development, with the mother's emotionally expressive face the site of the most potent visual stimulus. The choreographed oscillations and synchronizations of expressions and of glances in the mother-infant dyad create a mutual regulatory system of arousal that map, according to Tronick and Weinberg (1997), “elements of each interactant's state of consciousness into each of their brains" (p. 75). These researchers claim that the infant's limbic system, which is associated with the right hemisphere, is centrally involved in emotional communication (as well as in processing bodily experiences). Because this association persists into adulthood, the transfer of affect between infant

4 These three activities (receptivity, inward attendance, and communication/connection), define what the authors call the process of presence, as opposed to the therapist's preparations for presence and actual experiences when in presence (Geller \& Greenberg, 2012). 
and mother becomes a direct right brain linkage, forming the basis of what might best be described as intersubjectivity.

Intersubjectivity, or the shared relational space through which unconscious expressive material is communicated, has been described by many psychotherapists: Winnicott (1971), for example, speaks of potential space, Buber of the I-thou (1958), and Ogden (2004) of the analytic third. This is the space, according to Winnicott (1971), that both joins and separates the mother and child, the client and therapist, a space that is neither outside nor inside, neither objective nor subjective, a playful space where relationships are nourished and where culture begins. Ogden's description of the analytic third is particularly interesting in the way he describes the space between therapist and client as a separate agency, a third subjectivity that is "the product of a unique dialectic generated by/between the separate subjectivities of analyst and analysand within the analytic setting" and that "seems to take on a life of its own in the interpersonal field" (p. 169). The third position allows the analyst to attend to such relational psychodynamics as transference/countertransference and projective identification, a dynamic where subjectivities are subverted so that the recipient of the projection (the analyst) becomes for a moment the projector (the client). Through projective identification the therapist becomes a container for material the client is not yet ready to acknowledge or experience for himself.

How unconscious material is transferred directly from client to therapist is not fully understood. Schore (2000) suggests that "just as the left brain communicates its states to other left brains via conscious linguistic behaviors, so the right nonverbally communicates its unconscious states to other right brains that are tuned to receive these communications" (p. 76). This aligns with Trevarthen (1998), who states that intersubjectivity is manifested as an immediate sympathetic awareness of other's attentions, emotions, and intentions as these are transmitted through bodily movements and emotional expressions, especially those conveyed by the face, vocal tract, and hands. Nonverbal communication is pervasive in any human interaction and accompanies every utterance, with Beier and Young (1998) noting "even in written language authors convey 'nonverbal' structures, which tell us through channels such as continuity of words, unexpected phrasing, repetition, etc., more about the authors themselves than about their lexical message” (p. 243). For Beier and Young nonverbal behavior is the unconscious made visible, especially when there are discrepancies in messages between channels, such as facial expressions, verbal communication, tone of voice, gestures, and so on. They write, "because the cues and discrepancies among messages traveling in a variety of channels are subtle and appear ambiguous,...the meaning can stay hidden even from the sender and yet affect the emotions of the receiver" (p. 252).

To pick up these unconscious communications, Freud (1912) claimed the analyst "must adjust himself to the patient as a telephone receiver is adjusted to the transmitting microphone" (p. 115-116) and "turn his own unconscious like a receptive organ towards the transmitting unconscious of the patient” (p. 115). Freud called this 
state of attunement "evenly suspended attention" (p. 115). It was because the body inevitably gave away the unconscious that Freud was certain it could be known: "If his lips are silent, he chatters with his fingertips; betrayal oozes out of him at every pore. And thus the task of making conscious the most hidden recesses of the mind is one which is quite possible to accomplish" (Freud, 1997, p. 69).

\subsection{Mediated Therapeutic Presence}

So how do electronic representations of client and therapist affect therapeutic presence? What happens to the perceptions of client and therapist-and to the space in-between-when therapy is electronically mediated? How much do the media themselves intrude? For Stadter (2012) electronic media (smart phones, laptops, game controls, and tablets) insert themselves between two people, quite literally, as a clinging copresence he calls (echoing Ogden's analytic third) the $e$-third. The e-third "interferes with intimacy and reflection," Stadter claims, unlike "the intersubjective third which promotes reflective and intimate relating” (p. 11). Although appreciative of what the new communication technologies are offering his clients, Stadter (2013) describes many who are struggling hard in their lives to handle the social intrusiveness of this third thing that subsumes so many people's relational needs. ${ }^{5}$ According to Turkle (2011), the social intrusion of communication devices is leaving a whole generation of young people-the so-called digital natives-feeling cheated because parents and friends are never really present. What these youths yearn for, Turkle says, is "the pleasure of full attention, coveted and rare" (p. 266). They desire "time and touch, attention and immediacy" (p. 272). Because therapeutic presence provides "the pleasure of full attention, coveted and rare", therapy today, according to Stadter, is more valuable than ever, but the question remains to what extent the relational depths obtainable in therapeutic presence can be mediated. ${ }^{6}$

Reflecting on her own experiences with telephone psychoanalysis using Skype, Dettbarn (2013) has come to regard technology in the therapeutic setting more as the uncanny third. In its magical power to connect and in its inexplicable malfunctions and disconnects, Dettbarn claims, "The machine, a third party who suddenly determines the rules, becomes a part of our work" (p.18), an object like the therapist eliciting both positive and negative transferences. Dettbarn observes that the digital devices used

\footnotetext{
5 As Newitz (2007) describes so well in writing about his personal relationship with his laptop, "My laptop computer is irreplaceable...I love it. I would recognize the feel of its keyboard under my fingers in a darkened room...It doesn't just belong to me; I also belong to it” (p. 88).

6 Of course, therapists have as much difficulty as other people keeping their communications devices at bay-even during the therapeutic hour with a client. Wallwork, (2013), for instance, mentions psychotherapists confessing to reading emails, surfing the Internet, and checking text messages during telephone sessions.
} 
to make connections with the therapist can metamorphose into "evocative objects" (Turkle, 2007) taken by the client to "symbolically make and potentially maintain the connection [to the therapist] eternally, as when a Skype participant looks to see if his analyst is online around the clock." She goes on to say that "The beloved object has, as it were, become a living object, having settled somewhere between living and dead matter" (p.19). Moreover, if the therapist is experienced as a bad object, "malfunctions or disruptions in Skype are interpreted as confirmation of the analyst's aggression towards the analysand" (p. 20), with the uncanny third appearing to collude with the client against the therapist. If instead both client and therapist join forces against the uncanny third, forming a "double negative transference" (p. 22), working through can be prevented. In cases where the client has "attributed magical powers to the analyst" (p. 21), disruptions can result in premature disillusionment, upsetting the alliance. Because no one can control technological problems, Dettbarn claims, "the field of magic and the uncanny is activated" (p. 21).

Equally uncanny for Dettbarn (2013) is the disembodied voice. She asks, "Do our voices become disembodied on the computer? Are they ghostly voices? But who still believes in ghosts? Surely we have long since left this notion behind us. Or have we?... As the normally vibrant mark of our presence, does the voice lose its vitality in the absence of the body or does it lead us into an emotional area between the living and the dead?" (p. 20). Dettbarn is not alone here; other therapists and analysts have also spoken about the uncanniness of the disembodied voice in telephone sessions. For Brainsky (2003) the disembodied voice fosters "an unusually spectral relationship" (p. 23)-an "uncanny attachment" says Moses (2005, p. 28)-and hearing ghostly echoes in the room using a speakerphone left Leffert (2003) feeling "eerie." Freud (1915/1955), in his famous essay on the uncanny, connects uncanny feelings to a resurrection of outmoded animistic beliefs: "Nowadays we no longer believe in them, we have surmounted these modes of thought; but we do not feel quite sure of our new beliefs, and the old ones still exist within us ready to seize upon any confirmation" (p. 246). The telephone, as Connor (2000) in his history of ventriloquism writes, "still retains a tincture of the old supernatural explanations, and indeed begins to bring about a kind of re-enchantment of the world" (p. 42).

For other therapists, the telephone magnifies the presence of the absent body through the voice. Connor (2000) describes what is magnified by the telephone as a confluence of "pants, gasps, and hisses, pops, and percussions, of the breath sounding amid its originating body and amid the sensitive body of the telephone apparatus," making the sensorial experience of talking on the phone "like being coiled alongside your speaking twin, their lips pressed to your ear, and your lips murmuring into theirs" (p. 381). This coiled communication becomes for some therapists a connection that supports containment (Scharff, 2014), as reflected in Leffert's (2003) observation that the telephone "results in a purer, more intensely, even hyper-analytic process" ( $p$. 124) that is especially effective because it echoes the holding presence of the mother. Metaphorical references to the womb and the bonds between mother and child 
abound in descriptions of therapy by telephone. ${ }^{7}$ However, as Connor (2000) is quick to note, the voice over the telephone is "both more mechanical and more human than ordinary voices” (p. 381, emphasis added). Whereas Leffert emphasizes some of the more human, hyper-analytic aspects of therapy by telephone, Argentieri and Mehler (2003) are convinced that the mechanical inflections of the voice-the telephone's distortions of tones and inflections-interfere with communication between client and therapist. Indeed, one might ask how it is possible for the "hisses, pops, and percussions, of the breath"-the nonverbal expressions through which, as noted in the last section, the unconscious is revealed-are to be distinguished from the "hisses, pops, and percussions" of the interference on the line? As I have observed elsewhere, these interferences, or artifacts, are problematic precisely "because of their tendency to perturb (write over, jostle, and shove aside) the unconscious...expressions of human subjects," producing "impressions that do not originate with the subject but yet are often unconsciously confused with him” (Brahnam, 2012, p. 81).

Conventional wisdom would assume that adding a visual channel to distance psychotherapy would reunite voice and body, thereby enriching therapeutic presence. But that does not appear to be the case. Evidence suggests that, unlike face-to-face interactions, when a visual channel is available, it is used mostly to situate the interaction, with the audio channel becoming the focus of attention like it is with the telephone (Cukor et al., 1998). O'Donnell (1997), after presenting some evidence that bandwidth and screen size have little effect on people's preference for the audio channel in videoconferencing, speculates that video conferencing is missing some subtle yet unidentifiable elements that are essential for the proper utilization of the visual channel, rendering it "a sterile medium of limited value compared with a faceto-face meeting” (p. 315). Neuroscience provides clues to what might be missing. Schore (2000), for instance, presents powerful scientific evidence that subtle and implicit bodily interactions involving elaborate exchanges with others of corporeal expression matching, synchronizations, and rhythmical patterning, form the core of intersubjectivity. Beebe (2004) notes that "Interactions in the nonverbal and implicit modes are rapid, subtle, co-constructed, and generally out of awareness. And yet they profoundly affect moment-to-moment communication and the affective climate" (p. 49). In most teleconferencing systems available today, synchronization of audio and visual channels is imperfect, images are often distorted, and there are noticeable delays. Although Bayles (2012) realizes most therapists and clients accommodate the time lags that occur on Skype, she is concerned about the costs, "about the impact of the mismatching that can happen on Skype-both the minute, singular mismatches as well as ongoing failure to consistently meet and match” (p. 578).

7 As reflected, for instance, in these two quotes: "Does the offer of phone treatment break the boundary...stretching the umbilical cord?" (Moses, 2005, p. 29) and "The ringing of the phone symbolically represented 'the cry of the infant'....” (Rosenbaum, 1974, p. 490-491). 
Bayles's concerns are supported by evidence suggesting that audio/video mismatches, speed/pitch changes, timing misalignments, and delays have the potential of interrupting and attenuating the subtle nonverbal exchanges between people-sometimes producing unexpected effects. Massaro and Egan (1996), for example, found mismatches between visual and auditory displays registering as a third emotion (for instance, when happy audio content was played simultaneously with a video of a fearful facial expression, the resulting perception was surprise), and Tinwell and Grimshaw (2009) found that lack of synchronization between sound and lip movements in virtual characters produced perceived eeriness. In general, misalignment of audio and visual cues has been found to be confusing to viewers and to elicit negative emotions (Bruce, 1996). Recall in the last section how the unconscious is revealed through "discrepancies among messages traveling in a variety of channels...[where]...the meaning can stay hidden even from the sender and yet affect the emotions of the receiver" (Beier \& Young, 1998, p. 252). For therapists these audio/video mismatches and discrepancies can be unconsciously deceptive and disruptive, perturbing the feeling tones produced by the client's subtle and unconscious communications.

Tightly bound with the experience of the uncanny (unheimlich), as Freud (1915/1955) observed, is the experience of the familiar (heimlich). Mediated psychotherapy provokes the uncanny in part because it commingles the Heimlich with the Unheimlich. In our society people ordinarily communicate with each other using electronic devices, thus it seems perfectly natural to conduct therapy online or via telephone. ${ }^{8}$ Yet just as unresolved relational dynamics are magnified and intensified within the therapeutic setting, so too are media artifacts magnified and intensified. Echoes are heard, and a sort of ghost, a stranger in the room appears, in whose face and in whose voice is reflected, not so much a mirroring of the self as some shadow self. Cultures around the world tell stories of a mischievous shadow twin: one’s doppelgänger and harbinger of death (Rank, 1925/1971).

In reading the accounts of psychotherapists conducting therapy by telephone or Skype, there is a notable undercurrent of anxiety, often expressed as a rush to explain away an impending threat that makes being together in silence nearly intolerable:

Sometimes I have a feeling or experience, usually accompanied by mild anxiety, that the mechanical/psychological connection itself has been lost or broken. Patients may experience the same thing, asking, “Are you still there?” or saying, "I'm not hearing you.”...If I feel troubled by a silence or experience a sense of having "lost" the patient somewhere in it, I am more likely to interrupt it with a neutral question such as, "What's going on?" or "What's your thought?" or, more specifically, “I feel I've lost you.”...For some patients the activity provides necessary evidence of both the analyst's presence and empathic contact, while for others it can remove

8 In fact, this is a major argument for doing psychotherapy via the telephone or the Internet (see, for example, Scharff, 2014). 
a silence that could verge on a traumatic pressure to say too much too soon (Leffert, 2003, p. 121-122).

Accounts of sessions using Skype or the telephone are often punctuated, as in the example above, by expressions that eerily echo a medium's conjuring of spirits: “Are you there?...Are you still there?" Silence, rather than being a moment of communion, or of resistance, or of reflection, or of an emotional loss for words, becomes, instead, a reminder of loss, and for some, an occasion to panic.

At the moment of malfunction-when Dettbarn's uncanny third asserts itself with its power to connect and to disconnect-the absence of therapeutic presence can become painfully present. For Scharff (2014) such moments offer opportunities. For instance, she describes a situation early in therapy with a client when her headset failed: the client could hear her, but she could not hear him. The incident ended up revealing important dynamics between the client and his mother, which, through the process of working through, eventually fostered the therapeutic alliance. For Argentieri and Mehler (2003), however, mediated therapy is essentially traumatizing for both therapist and client precisely because it denies separation and loss and deprives the client of the bodily presence of the therapist, a traumatization poignantly described by this psychoanalytic candidate's account of her experiences with her training analyst:

On several occasions my analyst's phone was actually not working and he was not aware of the problem, which meant that I could not reach him. At other times there were problems with static in the line, poor reception, and dropped calls which required hanging up and redialing. These technical interferences in the line interrupted time, thought, and a sense of connection. It felt unsafe to have my analyst so far away and so silent, hidden from my emotions....It was not possible to jump on a plane and travel in the middle of a painful period where I needed the physical holding of my analyst's presence and the visual constancy of his office” (de Benaim, de Varela, de Setton, \& Anonymous, 2013, p. 200).

\subsection{Conclusion to Chapter 8}

In this chapter I have addressed how mediated psychotherapy (mostly via telephone and Skype) affects therapeutic presence and the shared relational space through which unconscious expressive material is communicated between therapist and client. Ogden (2004) calls this shared relational space the analytic third, which he describes in terms of a third subjectivity that "seems to take on a life of its own in the interpersonal field" (p. 169). For some therapists and psychoanalysts, technology becomes yet another presence that seems to take on a life of its own, an uncanny third (Dettbarn, 2013) or e-third (Stadter, 2012) that disrupts and intrudes upon the relational space between therapist and client. After discussing the uncanny third and e-third, I go on to show how therapeutic presence is potentially affected not only by the missing 
bodies of therapist and client (an important expressive modality of the unconscious and source of intersubjective resonance) but also by the addition of media artifacts that may unconsciously become confused with and alter the therapist's impressions and emotional reactions to the client's nonverbal expressions. ${ }^{9}$

A major goal of this chapter has been to bring to attention the effects media artifacts can potentially have on therapeutic presence and on the therapists who use their minds and bodies as sensitive instruments for receiving the unconscious communications of their clients. ${ }^{10}$ While some therapists are adapting to the new technologies, acknowledging the many conveniences offered by distance psychotherapy and its necessity in some cases, other therapists are expressing reservations about adopting these technologies, especially as the primary means of conducting therapy. Too often, however, their concerns are dismissed out of hand as resistances to change or as a lack of familiarity with the new technologies. However, as Short, Williams, and Christie (1976) early observed, people are aware of the degree of social presence offered by communications media and tend to avoid using a medium if they feel the degree of social interaction requires more social presence than the medium offers. It is reasonable to assume that therapists are equally aware of the degree of therapeutic presence offered by communications media and tend to avoid using a medium if they feel their interactions with clients require more therapeutic presence than the medium offers. Another goal of this chapter has been to show that therapist reservations are tenable and should be listened to carefully and taken more seriously.

Because the reader may be involved in the enterprise of designing technologies, my intention in this chapter is also to challenge researchers to do more to investigate the effects of media artifacts on person perception and on social presence and to encourage interface designers to consider the more subtle effects technologies can have on deeper forms of interpersonal communication and to think of ways of ameliorating some of their more obvious deleterious effects, especially when designing applications for distance psychotherapy. For example, can walls be stitched together virtually so that clients undertaking distance psychotherapy can have the feeling of containment that is offered by the visual constancy of a therapist's brick and mortar office? Or is it possible for a shared aural space or an unobtrusive sonic background to be designed such that it produces a feeling of containment and constancy? Or can methods be devised for gently alerting communication partners of a disconnection or of a device failure, such as a faulty headset? It is my hope that understanding more about therapeutic presence and how it is affected when mediated will put designers

9 Media artifacts potentially alter clients' impressions of therapists as well, but my focus in this chapter is on therapists since they use these feelings and impressions therapeutically in their work with clients.

10 I wish to stress that only a few media artifacts have been considered in this chapter; there are many more (see, for instance, Cukor et al., 1998). 
and developers in a better position to appreciate the necessity of supporting and of protecting it when designing future systems for distance psychotherapy. ${ }^{11}$

\section{References}

Ainsworth, M. (2002). ABC's of "internet therapy": E-therapy history and survey. http://www. metanoia.org/imhs/history.htm. Accessed December, 2013.

Alexander, F., \& French, T. M. (1946). Psychoanalytic therapy. New York: Ronald Press.

Alexander, J. F., Holtzworth-Munroe, A., \& Jameson, P. B. (1994). The process and outcome of marital and family therapy: Research review and evaluation. In A. E. Bergin \& S. L. Garfield (Eds.), Handbook of psychotherapy and behavior change (4th ed., pp. 595-630). New York: John Wiley \& Sons, Inc.

Argentieri, S., \& Mehler, J. A. (2003). Telephone 'anaysis': 'Hello, who's speaking?' Insight, 12, 17-19.

Bachelor, A., \& Horavath, A. (1999). The therapeutic relationship. In M. A. Hubble, B. L. Duncan \& S. D. Miller (Eds.), The heart and soul of change: What works in therapy (pp. 133-178). Washington, DC: American Psychological Association.

Barak, A., Hen, L., Boniel-Nissim, M., \& Shapira, N. (2008). A comprehensive review and a meta analysis of the effectiveness of internet-based psychotherapeutic intervention. Journal of Technology in Human Services, 26(2/4), 109-160.

Barber, J. P., Khalsa, S.-R., \& Sharpless, B. A. (2010). The validity of the alliance as a predictor of psychotherapy outcome. In J. C. Muran \& J. P. Barber (Eds.), The therapeutic alliance: An evidence-based guide to practice (pp. 29-43). New York: John Wiley and Sons.

Barfeld, W., Zeltzer, D., Sheridan, T. B., \& Slater, M. (1995). Presence and performance within virtual environments. In W. Barfield \& T. A. Furness (Eds.), Virtual environments and advanced interface design (pp. 473-541). Oxford: Oxford University Press.

Bayles, M. (2012). Is physical proximity essential to the psychoanalytic process? An exploration through the lens of skype? Psychoanalytic Dialogues, 22, 569-585.

Beebe, B. (2004). Faces in relation. Psychoanalytic Dialogues, 14(1), 1-51.

Beier, E. G., \& Young, D. M. (1998). The silent language of psychotherapy: Social reinforcement of unconscious process (3rd ed.). New York: Aldine De Gruyter.

Bordin, E. S. (1979). The generalizability of the psychoanalytic concept of working alliance. Psychotherapy: Theory, Research, Practice, Training, 16, 252-260.

Brahnam, S. (2009). Building character for artificial conversational agents: Ethos, ethics, believability, and credibility. PsychNology Journal, 7(1), p. 9-47.

Brahnam, S. (2012). To hear-to say: The mediating presence of the healing witness. Al \& Society, 27(1), 53-90.

Brainsky, S. (2003). Adapting to, or idealizing, technology? Insight, 12, 22-24.

Bruce, V. (1996). The role of the face in communication: Implication for video design. Interacting with Computers, 8, 166-176.

Buber, M. (1958). I-Thou (R. G. Smith, Trans.). New York: Charles Scribner's Sons.

Castonguay, L. G., Constantino, M. J., \& Grosse, H. M. (2006). The working alliance: Where are we and where should we go? Psychotherapy: Theory, Research \& Practice, 43, 271-279.

11 Interface and systems designers might at least consider the effect their systems have on therapeutic presence by measuring it when designing products for distance psychotherapy (see, for instance, the instrument for measuring therapeutic presence devised by Geller, Greenberg, \& Watson, 2010). 
Connor, S. (2000). Dumbstruck: A cultural history of ventriloquism. Oxford: Oxford University Press. Crossley, N. (1996). Intersubjectivity: The fabric of social becoming. London: Sage.

Cukor, P., Baer, L., Willis, B. S., Leahy, L., O’Laughlen, J., Murphy, M., M., Withers, M., \& Martin, E. (1998). Use of videophones and low-cost standard telephone lines to provide a social presence in telepsychiatry. Telemedicine Journal, 4(4), 313-321.

Cushman, P. (1992). Psychotherapy to 1992: A historically situated interpretation. In D. K. Freedheim \& H. J. Freudenberger (Eds.), History of psychotherapy: A century of change (pp. 21-64). Washington, DC: American Psychological Association.

de Benaim, B. S., de Varela, Y. G., de Setton, L. S., \& Anonymous. (2013). Four women analysts reflect on their teleanalyses when candidates. In J. S. Scharff (Ed.), Psychoanalysis online: Mental health, teletherapy and training (pp. 195-207). London: Karnac.

Dettbarn, I. (2013). Skype as the uncanny third. In J. S. Scharff (Ed.), Psychoanalysis online: Mental health, teletherapy, and training (pp. 15-25). London: Karnac Books Ltd.

Eubanks-Carter, C., Muran, J. C., \& Safran, J. D. (2010). Alliance ruptures and resolution. In J. C. Muran \& J. P. Barber (Eds.), The therapeutic alliance: An evidence-based guide to practice ( $\mathrm{pp}$. 74-94). New York: John Wiley and Sons.

Freud, S. (1912). Recommendations to physicians practicing psycho-analysis. In J. Strachey (Ed.), The standard edition of the complete psychological works of Sigmund Freud (Vol. 12, pp. 111-120). New York: W. W. Norton \& Company.

Freud, S. (1915/1955). The Uncanny. The standard edition of the complete psychological works of Sigmund Freud (Vol. 17). London: Hogarth.

Freud, S. (1959). Analysis of a phobia in a five-year-old boy. Collected Papers (Vol. 3). New York: Basic Books.

Freud, S. (1997). Dora: An analysis of a case of hysteria. New York: Touchstone.

Friedberg, R. D., Tabbaraha, S., \& Poggesia, R. M. (2013). Therapeutic presence, immediacy, and transparency in CBT with youth: Carpe the moment! The Cognitive Behaviour Therapist, 6(Jan): e12.

Geller, S. M., \& Greenberg, L. S. (2002). Therapeutic presence: Therapists“ experience of presence in the psychotherapeutic encounter. Person-Centered and Experiential Psychotherapies, 1, 71-86.

Geller, S. M., \& Greenberg, L. S. (2012). Therapeutic Presence: A mindful approach to effective therapy. Washington, DC: American Psychological Association.

Geller, S. M., Greenberg, L. S., \& Watson, J. C. (2010). Therapist and client perceptions of therapeutic presence: The development of a measure. Psychotherapy Research, 20, 599-610.

Gelso, C. J., \& Hayes, J. A. (1998) The psychotherapy relationship: Theory, research, and practice. New York: John Wiley \& Sons, Inc.

Gove, P. B. (Ed.). (1986). Webster's third new international dictionary of the english language unabridged. Springfield, MA: Merriam-Webster Inc., Publishers.

Grotijahn, M. (1955). Six letters to an analyst by an adolescent Girl. Jake Gimbel Lectures. Stanford University.

Grumet, G. W. (1979). Telephone therapy: A review and case report. American Journal of Orthopsychiatry, 49, 574-584.

Hilty, D. M., Marks, S. L., Urness, D., Yellowlees, P. M., \& Nesbitt, T. S. (2004). Clinical and educational telepsychiatry applications: A review. Canadian Journal of Psychiatry, 49(1), 12-23.

Hornblow, A. R., \& Sloane, H. R. (1980). Evaluating the effectiveness of a telephone counseling service. British Journal of Psychiatry, 137, 337-338.

Kokotovic, A. M., \& Tracey, T. J. (1990). Working alliance in the early phase of counseling. Journal of Counseling Psychology, 37, 16-21.

Koocher, G. P. (2007). Twenty-first century ethical challenges for psychology. American Psychologist, 62(5), 375-384. 
Lambert, M. J. (1992). Psychotherapy outcome research: Implications for integrative and eclectical therapists. In M. R. Goldfried (Ed.), Handbook of psychotherapy integration (pp. 94-129). New York: Basic Books.

Leffert, M. (2003). Analysis and psychotherapy by telephone: Twenty years of clinical experience. Journal of the American Psychoanalytic Association, 51, 101-130.

Lester, D. (2006). Etherapy: Caveats from experiences with telephone therapy. Psychological Reports, 99, 894-896.

Lombard, M., \& Ditton, T. (1997). At the heart of it all: The concept of presence. Journal of ComputerMediated Communication, 3(2). DOI: 10.1111/j.1083-6101.1997.tb00072.x.

Lu, S., Harter, D., \& Pierce, D. (2011). Potentials and challenges of using virtual environments in psychotherapy. Annals of Psychotherapy \& Integrative Health, 14(1), 56-66.

Martin, D. J., Garske, J. P., \& Davis, M. K. (2000). Relation of the therapeutic alliance with outcome and other variables: A meta-analytic review. Journal of Consulting and Clinical Psychology, 68(3), 438-450.

Massaro, D. W., \& Egan, P. B. (1996). Perceiving affect from the voice and the face. Psychonomic Bulletin and Review, 3(2), 215-221.

Maxmen, J. (1976). The post-physician era: Medicine in the 21st century. New York: John Wiley \& Sons.

Merleau-Ponty, M. (1964). The primacy of perception. Evanston, IL: Northwestern University Press.

Meyerbröker, K., \& Emmelkamp, P. M. G. (2011). Virtual reality exposure therapy for anxiety disorders: The state of the art. In S. Brahnam \& L. C. Jain (Eds.), Virtual reality in psychotherapy, rehabilitation, and assessment (pp. 47-62). Berlin Heidelberg: Springer-Verlag.

Moses, I. (2005). Controversial discussions: Telephone analysis, treatment by telephone: An uncanny attachment. Psychologist-Psychoanalyst Official Publication of Division 39 of APA, 15(4), 28-29.

Newitz, A. (2007). My laptop. In S. Turkle (Ed.), Evocative objects (pp. 88-91). Cambridge: MIT Press.

Norcoss, J. C. (2010). The therapeutic relationship. In B. L. Duncan, S. D. Miller, B. E. Wampold \& M. A. Hubble (Eds.), The heart and soul of change: Delivery what works (2nd ed., pp. 113-141). Washington, DC: American Psychological Association.

O’Donnell, C. P. (1997). A nod is as good as a wink...or is it? A critical review of social psychology involved in video conferencing. http://www.psy.gla.ac.uk/ steve/crvid.html. Accessed December, 2013.

Ogden, T. H. (2004). The analytic third: Implications for psychoanalytic theory and technique. Psychoanalytic Quarterly, LXXIII, 167-195.

Owens, H. (1970). Hypnosis by phone. American Journal of Clinical Hypnosis, 13, 57-60.

Rank, O. (1925/1971). Double: A psychoanalytic study (H. Tucker, Trans.). Chapel Hill: The University of North Carolina Press.

Rees, C. S., \& Haythornthwaite, S. (2004). Telepsychology and videoconferencing: Issues, opportunities and guidelines for psychologists. Australian Psychologist, 39(3), 212-219.

Rees, C. S., \& Stone, S. (2005). Therapeutic alliance in face-to-face versus videoconferenced psychotherapy. Professional Psychology: Research and Practice, 36, 649-653.

Reynolds, D. J., Jr., Stiles, W. B., \& Grohol, J. M. (2006). An investigation of session impact and alliance in Internet based psychotherapy: Preliminary results. Counseling and Psychotherapy Research, 6, 164-168.

Riva, G. (2005). Virtual reality in psychotherapy: Review. CyberPsychology \& Behavior, 8(3), 220-230. Rosenbaum, M. (1974). Continuation of psychotherapy by “long distance” telephone. International Journal of Psychoanalytic Psychotherapy, 3, 483-495.

Scharff, J. S. (2014). Clinical issues in analyses over the telephone and the internet. In A. Lemma \& L. Caparrotta (Eds.), Psychoanalysis in the technoculture era (pp. 47-61). London and New York: Routledge. 
Schore, A. (2000). Affect regulation and the repair of the self. Hillsdale, NJ: Erlbaum.

Short, J., Williams, E., \& Christie, B. (1976). The social psychology of telecommunications. London, New York, Sydney, Toronto: John Wiley \& Sons.

Stadter, M. (2012). Presence and the present: Relationship and time in contemporary psychodynamic therapy. New York: Jason Aronson.

Stadter, M. (2013). The influence of social media and communications technology on self and relationships. In J. S. Scharff (Ed.), Psychoanalysis online: Mental health, teletherapy and training (pp. 3-14). London: Karnac Books Ltd.

Stiles, W. B., \& Goldsmith, J. Z. (2010). The alliance over time. In J. C. Muran \& J. P. Barber (Eds.), The therapeutic alliance: An evidence-based guide to practice (pp. 44-62). New York: John Wiley and Sons.

Tinwell, A., \& Grimshaw, M. (2009). Survival horror games: An uncanny modality. Paper presented at the Thinking After Dark Conference, Montreal, Canada. http://data.bolton.ac.uk/cet/JGVW_ Tinwell_et_al.pdf. Accessed December, 2013.

Trevarthen, C. (1998). Intersubjectivity. In R. Wilson \& F. Keil (Eds.), The MIT Encyclopedia of Cognitive Science (pp. 415-419). Cambridge: MIT Press.

Tronick, E. Z., \& Weinberg, M. K. (1997). Depressed mothers and infants: Failure to form dyadic states of consciousness. In L. Murray \& P. J. Cooper (Eds.), Postpartum depression and child development (pp. 54-81). New York: Guilford Press.

Turkle, S. (2007). Evocative Objects. Cambridge: MIT Press.

Turkle, S. (2011). Alone together: Why we expect more from technology and less from each other. New York: Basic Books.

Turner, J. W. (2006). Telepsychiatry as a case study of presence: Do you know what you are missing? Journal of Computer-Mediated Communication, 6(4). DOI: 10.1111/j.1083-6101.2001.tb00132.x.

Villani, D., Riva, F., \& Riva, G. (2007). New technologies for relaxation: The role of presence. International Journal of Stress Management, 14(3), 260-274.

Wallwork, E. (2013). Skype as the uncanny third. In J. S. Scharff (Ed.), Psychoanalysis online: Mental health, teletherapy, and training (pp. 85-94). London: Karnac Books Ltd.

Winnicott, D. W. (1971). Playing and reality. London: Routledge. 